\title{
Editorial \\ Shame!!! Everyone knows that. The case for practitioners to write up their practice
}

\section{Anaru Eketone}

I had just started off as a lecturer in a university. I knew that I was expected to publish, but I had not really grasped the fact that part of writing is that it has to be something for others to read. I had only thought about the creative process, not expecting others to read and critique it. I put something together based on an assignment I had written for my social work diploma. It was about some particular Māori concepts in practice but when I had finished, I thought to myself something along the lines of, 'Shame!!! Everyone knows that'. In some ways I was right; most Māori practitioners knew about what I was writing, would probably agree with me, in fact there was little if anything new in what I was writing. Despite my anxiety I was persuaded to send it in and then I waited for the rejection.

To my surprise it wasn't rejected and the journal went ahead and published it. I didn't tell anyone that it had been published and tried to keep my head down as I expected everyone who would read it would sneer at it and say things like, 'so what?', or 'how did this get published?', or 'the journal's standards are slipping'. Despite my misgivings, no-one has ever said a bad word about it (to my face); in fact it has been the one thing I have written that has had consistently good things said about it.

There were a number of things I learnt out of that experience. The first is my lack of confidence that I would have much to say that would be of value to others. I thought I was just repeating what most people in the sector already knew and in some ways I was, but that leads to my next point. There is very little published on Māori social and community work theory and practice. So little, in fact, that for the social work students who are enrolled in the course I teach, most of the required readings are not written by Māori social work practitioners. We have to fill it with overseas and local writers and adapt them to our needs. We as a Māori professional workforce need to write and publish more material about what supports, informs and directs our practice.

It is not just students who need more practice-informed writings. A consequence of the lack of published material is that it can be a struggle at times to implement culturally effective programmes, services and approaches in mainstream organisations. I found that when I worked in the community, with mainstream bosses, it was sometimes very difficult for them to accept some of my approaches as these did not always fit in with the 'orthodox' ways they were used to. I knew my approaches were right for the Māori community I was working in, but I had no proof or validation that I could show to them in a way that they would accept. They had more tertiary qualifications than me, they had a higher job title than me, they were earning more money than me, so my saying, 'trust me, I know what I'm doing' did not convince them that my departure from their way of doing things was worth the risk.

It actually comes down to how knowledge is validated. When academics talk about epistemology, what they are asking is, 'how do you know that your knowledge is valid?' 
For some of us validation of our knowledge comes through whether it is useful, for some it comes from personal experience, for others it is the origin of that knowledge, be it academia, scripture or people we trust. For some, 'my kuia said', is all the validation they need for what is true, or for what processes they should follow.

We live in a western world that values knowledge that has gone through some form of scientifi or academic rigour, where other experts have examined the way in which the knowledge was gained and determined that the interpretations of the findings are trustworthy and valid. These findings are then published and the knowledge is shared and discussed. Whether we like it or not, that is the dominant approach of a lot of the people who hold the purse-strings for our organisations or hold sway over how services are delivered.

Because the article I was previously talking about was now published knowledge, my point of view became more acceptable in the mainstream and I have continued to find that. The more that is written and can be backed up by our own practice and experience, the greater the reception of Māori approaches by those from the mainstream. In one job I had, the Pākehā team leader that I would have the most animated discussion with over my practice, refused to believe that my approach was valid. I left that job never convincing them that a community-based approach based on reciprocity would ever be acceptable. Six months later as a new lecturer in the Department of Community and Family Studies at the University of Otago, I presented a paper at a conference stating precisely the points I had always argued for. After my presentation there was a lot of support and discussion where, because of the position I now held, my experience and point of view were considered valid. The thing that made me smile was that the old team leader was sitting in the audience with crossed arms, grumpy face slipping further and further down their seat as I talked. Game, set and match, I thought!

Some practitioners responded to our call in the last Te Kömako for examples on how they practise and so we are excited to publish them in this issue. We hope to make this an ongoing part of future Te Kōmako editions. They are valuable to our up-and-coming students, as we like to give them a range of Māori approaches because we all know there is not just one Māori way of doing things. These types of writings are also particularly valuable for those working in areas where Māori staff, knowledge and processes are not understood or supported. Having successful, tried and tested ways of operating can be very useful for them in justifying to their managers why their Māori-based approaches are useful and valid. We also have an article from Paora Moyle outlining what she had to do to get her Master's degree. We have included both these types of articles so that other practitioners may be encouraged and inspired to consider writing and pursuing further study.

Getting our knowledge, theory and practice into the wider community is vital for the development of Māori social and community work practice. There is still far too little written and we have hundreds of successful practitioners and thinkers out there that have much to offer the field. We need more examples of practice frameworks, of Māori and iwi-based processes and models; we need more examples that have emerged from years of practice, even if we are tempted to think, 'Shame!!! Everyone knows that'. 